\title{
A GESTÃO DO CONHECIMENTO NO SETOR PÚBLICO: UM DIAGNÓSTICO PRELIMINAR SOBRE PRÁTICAS E FERRAMENTAS UTILIZADAS NO INSTITUTO MINEIRO DE AGROPECUÁRIA - IMA
}

KNOWLEDGE MANAGEMENT IN THE PUBLIC SECTOR: A PRELIMINARY DIAGNOSTIC OF PRACTICES AND TOOLS UTILIZED AT INSTITUTO MINEIRO DE AGROPECUÁRIA - IMA

Paula Brayner Souto Maior Lima Fundação Pedro Leopoldo, Minas Gerais paulabsml@hotmail.com

Maria Celeste Reis Lobo de Vasconcelos Fundação Pedro Leopoldo, Minas Gerais celestevasconcelos@gmail.com

Jorge Tadeu de Ramos Neves Universidade FUMEC / Escola de Ciência da Informação - UFMG jtrneves@gmail.com

Simone Cristina Dufloth Fundação João Pinheiro, Minas Gerais $\underline{\text { sduf@uol.com.br }}$

Submissão: $28 / 10 / 2013$ Aprovação: 25/09/2015 


\title{
RESUMO
}

O objetivo deste artigo é apresentar as práticas e ferramentas de gestão do conhecimento identificadas no Instituto Mineiro de Agropecuária, a partir da realização de um estudo de caso, de caráter descritivo. Os dados foram obtidos por meio da aplicação de questionários, respondidos por um total de 65 servidores. Os portais colaborativos como a intranet e extranet estão entre as práticas utilizadas com muita frequência. No que concerne aos processos essenciais da gestão do conhecimento, foi observado que o compartilhamento do conhecimento é realizado com frequência, tanto de maneira formal quanto informal, e que os elementos de identificação, aquisição, desenvolvimento, utilização, retenção do conhecimento estão presentes no cotidiano dos servidores, ainda que esporadicamente.

Palavras-chaves: práticas e ferramentas de GC; processos essenciais do conhecimento; organização pública

\begin{abstract}
This article aims to present the practices and tools of knowledge management that were identified at Instituto Mineiro de Agropecuária, through a preliminary case study of descriptive character. Data were obtained by means of questionnaires that were answered by a total number of 65 civil servants. The collaborative tools such as intranet and extranet are among the practices that are used very often. Regarding the essential knowledge processes, it was verified that knowledge is frequently shared, in both formal and informal way and that the elements of knowledge identification, knowledge acquisition, knowledge development, knowledge utilization and knowledge preservation are present in the daily routine of the respondents, although not regularly.
\end{abstract}

Keywords: practices and tools of KM; knowledge essential processes; public organization 


\section{Introdução}

Cada vez mais é reconhecido que o bem mais valioso que uma organização possui é o conhecimento. Ele passa a ser o novo motor da economia na Sociedade do Conhecimento, transformando-se no principal fator de produção. Logo, uma organização poderá se tornar mais competitiva quanto mais capaz for de adquirir e aplicar o conhecimento que possui. Por isso, é tão importante gerenciá-lo (ANGELONI, 2008).

A gestão do conhecimento (GC) é entendida como um procedimento gerencial cujo foco está na aquisição, geração, transferência e compartilhamento, além do uso ininterrupto de conhecimento. Nessa nova era, o conhecimento de cada indivíduo valoriza-se cada vez mais dentro das empresas, pois elas veem nele a oportunidade de se tornarem mais competitivas, por meio do compartilhamento de experiências e da aprendizagem organizacional (VASCONCELOS, 2000).

Portanto, a sociedade atual deve estar atenta ao compartilhamento de informações e conhecimentos estratégicos e, como diferencial competitivo, a criação de novos conhecimentos, o que a distingue da chamada sociedade industrial, que tinha como principal característica a eficiência e a especialização e, como diferencial competitivo, a capacidade de resolução de rotinas físicas e intelectuais de forma rápida (REIS, 2007).

A GC se preocupa em aproveitar os recursos existentes nas organizações de forma a agregar valor e sentido às informações para desenvolver um modelo de aplicação prática em diversas áreas do conhecimento. Desse modo, a base do conhecimento organizacional passa por mudanças regulares, o que segundo Probst, Raub e Romhardt (2002) define o processo de aprendizagem organizacional. A adoção da gestão do conhecimento gera mudanças que produzem efeitos não só no setor privado, como também no setor público, e veem acompanhadas de reestruturação de ações e processos.

Todavia, Santos (2007) afirma que nas instituições públicas, a gestão do conhecimento requer adequação gradual desse novo modelo de gestão, com vistas ao acoplamento ou à inserção ao modelo de gestão já existente. O autor acrescenta que, mesmo que as organizações públicas sejam notadamente intensivas em conhecimento, geralmente não possuem uma cultura e um 
ambiente voltados para a aprendizagem organizacional e para a inovação e, salvo algumas exceções, também não incentivam a educação continuada de seus servidores.

Um cenário de modernização pode ser favorável a práticas inovadoras dentro das organizações, inclusive das públicas. No Estado de Minas Gerais, por exemplo, a partir de 2003, tiveram início vários projetos de modernização de todas as entidades do governo. Dentre eles, Neves e Silva (2009) citam o "Choque de Gestão, Pessoas e Qualidade e Inovação na Administração Pública", elaborado com o objetivo de melhorar a qualidade dos serviços públicos, mediante a reorganização do arranjo institucional e do modelo de gestão do Estado. Inserido nesse ambiente de modernização institucional está o Instituto Mineiro de Agropecuária- IMA, organização pública vinculada à Secretaria de Estado de Agricultura, Pecuária e Abastecimento, de Minas Gerais.

Este artigo tem como objetivo apresentar um diagnóstico preliminar das práticas e ferramentas de gestão do conhecimento adotadas pelo IMA. Para atingir seus objetivos, o artigo está estruturado em cinco tópicos, quais sejam: tópico um, a introdução; que apresenta o contexto da pesquisa. O tópico dois descreve alguns modelos de gestão do conhecimento descritos na literatura; além da importância da gestão do conhecimento no setor público. $\mathrm{O}$ tópico três consiste da metodologia utilizada, seguido pelo tópico quatro que mostra os resultados obtidos e do tópico cinco que contém as principais conclusões do trabalho.

\section{Conhecimento e Gestão do Conhecimento}

Conhecimento representa a soma das experiências do indivíduo ou da coletividade, é cumulativo. Para Setzer (1999), o conhecimento não pode ser descrito por completo e nem depende apenas de uma interpretação pessoal, como a informação, pois exige uma vivência do objeto do conhecimento. Segundo Probst, Raub e Romhardt (2002, p.29):

Conhecimento é o conjunto total incluindo cognição e habilidades que os indivíduos utilizam para resolver problemas. Ele inclui tanto a teoria quanto a prática, a regras do dia a dia e as instruções como agir. O conhecimento baseia-se em dados e informações, mas, ao contrário deles, está sempre ligado a pessoas. Ele é construído por indivíduos e representa suas crenças sobre relacionamentos causais.

Face ao desafio de gerenciar o conhecimento organizacional, estruturá-lo e sistematizá-lo de modo a atingir objetivos e metas institucionais e a obter vantagens competitivas, ocorre o 
processo de gestão do conhecimento. Assim, conforme afirma Vasconcelos (2000), a gestão da inovação e do conhecimento assume, pois, um elevado grau de importância e relevância para as empresas de todos os setores da economia, que devem focar suas atenções em aquisição, geração, compartilhamento e registro do conhecimento. Para Alvarenga Neto (2005), uma gestão voltada para o conhecimento é aquela capaz de estabelecer uma visão estratégica para o uso da informação e do conhecimento. É capaz, ainda, de promover aquisição, criação, codificação parcial e transferência de conhecimentos tácitos e explícitos, estimulando a criatividade, a inovação, a aprendizagem, além da educação continuada.

Os autores Probst, Raub e Romhardt (2002) propõem, em seu modelo, que a gestão do conhecimento é composta pelos seguintes processos essenciais:

- Identificação do conhecimento - consiste em identificar os conhecimentos internos e externos importantes para a empresa;

- Aquisição de conhecimento - a empresa busca integrar conhecimento externo à sua base de conhecimento;

- Desenvolvendo conhecimento - a organização se esforçará na construção de novas habilidades, competências, ideias e produtos a partir do desenvolvimento do conhecimento;

- Distribuição ou compartilhamento de conhecimento - é o processo de disseminar conhecimento que já está presente na organização;

- Utilização do conhecimento - processo que garantirá que o conhecimento seja aplicado na organização para alcançar resultados visíveis;

- Preservação ou retenção de conhecimento - é quando acontece a seleção do conhecimento que merece ser guardado. Esta fase é fundamental para garantir a memória da empresa, evitando perdas de conhecimento durante sua existência.

Já Angeloni (2008) ressalta três dimensões nas quais é possível se aplicar a gestão do conhecimento: a dimensão pessoas, que consiste em práticas relacionadas aos aspectos da gestão de recursos humanos que facilitam a transferência, a disseminação e o compartilhamento de informações e conhecimento; a dimensão processo, que se refere às práticas ligadas primariamente à estruturação dos processos organizacionais que funcionam como facilitadores de geração, retenção, organização e disseminação do conhecimento organizacional; a dimensão tecnologia, referente às práticas cujo foco central consiste na base tecnológica e funcional a qual serve de suporte à gestão do conhecimento organizacional e 
inclui automação da gestão da informação, aplicativos e ferramentas de tecnologia da informação para captura, difusão e colaboração.

No entanto, para que a organização consiga difundir e implantar um processo de gestão do conhecimento precisa colocar em sua rotina as chamadas Práticas de Gestão do Conhecimento, que, para Batista (2004), são práticas de gestão organizacional voltadas para produção, retenção, disseminação, compartilhamento e aplicação do conhecimento dentro das organizações, bem como na relação dessas com o mundo exterior.

Embora as organizações públicas possuam propósitos diversos das organizações privadas, segundo Coelho (2004), as estratégias e as tecnologias utilizadas para a consecução de seus objetivos tendem a ser semelhantes. Assim, as discussões acerca das práticas de gestão do conhecimento vêm sendo difundidas também na esfera pública.

Tomando como base um estudo realizado em organizações públicas de países-membros da Organização para Cooperação e Desenvolvimento Econômico (OCDE) em 2003, Batista et al (2005) pesquisaram práticas e ferramentas de GC e mudanças estruturais e culturais ocorridas em 27 entidades públicas do Poder Executivo Federal do Brasil, resultantes da implantação da GC. Outras pesquisas no setor público podem ser citadas como a de Gonçalves (2010), que identificou 45 práticas e ferramentas relacionadas à Gestão do Conhecimento na Administração Tributária de Minas Gerais - ATMG, que foram agrupadas segundo o modelo de Angeloni (2008). Outros resultados se encontram em Gonçalves et al. (2012).

Observa-se que os debates sobre Gestão do Conhecimento no setor público são crescentes, mostrando a importância de pesquisas nesta área. Um exemplo disso é a publicação recente de Batista (2012), que propõe um modelo de GC para Administração Pública baseado em seis componentes: i) direcionadores estratégicos: visão, missão, objetivos estratégicos, estratégias e metas; ii) viabilizadores: liderança, tecnologia, pessoas e processos; iii) processos de GC: identificar, criar, armazenar, compartilhar e aplicar; iv) ciclo KDCA; v) resultados de GC; vi) partes interessadas: cidadão-usuário e sociedade. Os estudos de Batista serão usados como modelo teórico de análise neste artigo.

O próximo item apresenta a metodologia adotada na pesquisa no IMA. 


\section{Metodologia}

A pesquisa em questão seguiu as diretrizes do estudo realizado por Batista et al (2005) para a identificação de práticas e ferramentas de gestão de conhecimento. Tal escolha se deve ao fato desse estudo investigar o estágio de implantação e alcance da GC nas organizações públicas, abrangendo, ainda, a percepção dos pesquisados acerca do uso e do conhecimento das práticas e ferramentas propostas. Para verificar a presença e o uso dos processos essenciais da GC (identificação, aquisição, desenvolvimento, compartilhamento, utilização e retenção do conhecimento) na rotina dos servidores do IMA, foi utilizado o modelo de Probst, Raub e Romhardt (2002), o qual permite uma visão sistêmica dos elementos construtivos da gestão do conhecimento em uma organização, a partir do posicionamento dos respondentes frente a questões específicas.

O estudo de caso único foi a metodologia escolhida para essa pesquisa, pois segundo Yin (2001/1984) esse método é utilizado em situações em que os comportamentos relevantes não podem ser manipulados, mas nas quais é possível se fazer observações diretas e entrevistas sistemáticas. $\mathrm{O}$ universo pesquisado foram os servidores do Instituto Mineiro de Agropecuária, que conta atualmente com 1649 servidores. Para o objetivo de identificação de práticas da gestão do conhecimento, foram entrevistas: a Gerência de Planejamento e Modernização Institucional e a Gerência de Recursos Humanos por se tratar de setores diretamente envolvidos com o tema em questão.

Para a análise de percepção da adoção das práticas de gestão do conhecimento e dos impactos esperados pela implantação da Gestão do Conhecimento, todos os servidores da instituição foram contactados, a partir da disponibilização de um questionário estruturado na intranet da instituição, utilizando-se a ferramenta Google Docs. A amostra final foi composta por 65 servidores. A pesquisa foi dividida em duas partes: na primeira foram enviados questionários idênticos à gerente de Planejamento e Modernização Institucional e ao gerente de Recursos Humanos visando à identificação das práticas de gestão do conhecimento existentes no IMA e, ainda, o estágio de implantação e o alcance das práticas de GC. Nessa etapa também foram verificados documentos da instituição com o objetivo de identificar práticas e ferramentas de GC possivelmente utilizadas no cotidiano dos servidores. A seguir foi realizada a coleta de dados do perfil dos respondentes, tais como: tempo de serviço na organização, unidade (setor) 
em que trabalha e grau de instrução. Para verificação de conhecimento e frequência de uso de práticas e ferramentas de Gestão do Conhecimento por esses servidores, o questionário utilizado foi o mesmo enviado às gerências contatadas na primeira etapa. Foi realizado ainda o teste do qui-quadrado para verificar a existência de diferenças significativas entre as respostas de servidores com mais de 10 anos de trabalho no IMA e menos de 10 anos de trabalho no IMA.

\section{Resultados Obtidos}

Neste item são apresentados: o perfil dos respondentes, a percepção dos gestores e servidores quanto às práticas de GC e a análise dos dados da pesquisa.

\subsection{Perfil dos respondentes}

No que concerne ao perfil dos respondentes, no quesito gênero, a maior parte dos servidores é do sexo masculino (62\%). Quanto ao grau de instrução, a Figura 1 mostra que a maioria dos respondentes (49\%) possui pós-graduação em nível Lato Sensu. O alto grau de escolaridade apresentado pelos respondentes pode sinalizar que essa característica venha a ser um fator facilitador na implementação de ações mais modernas e inovadoras pela autarquia.

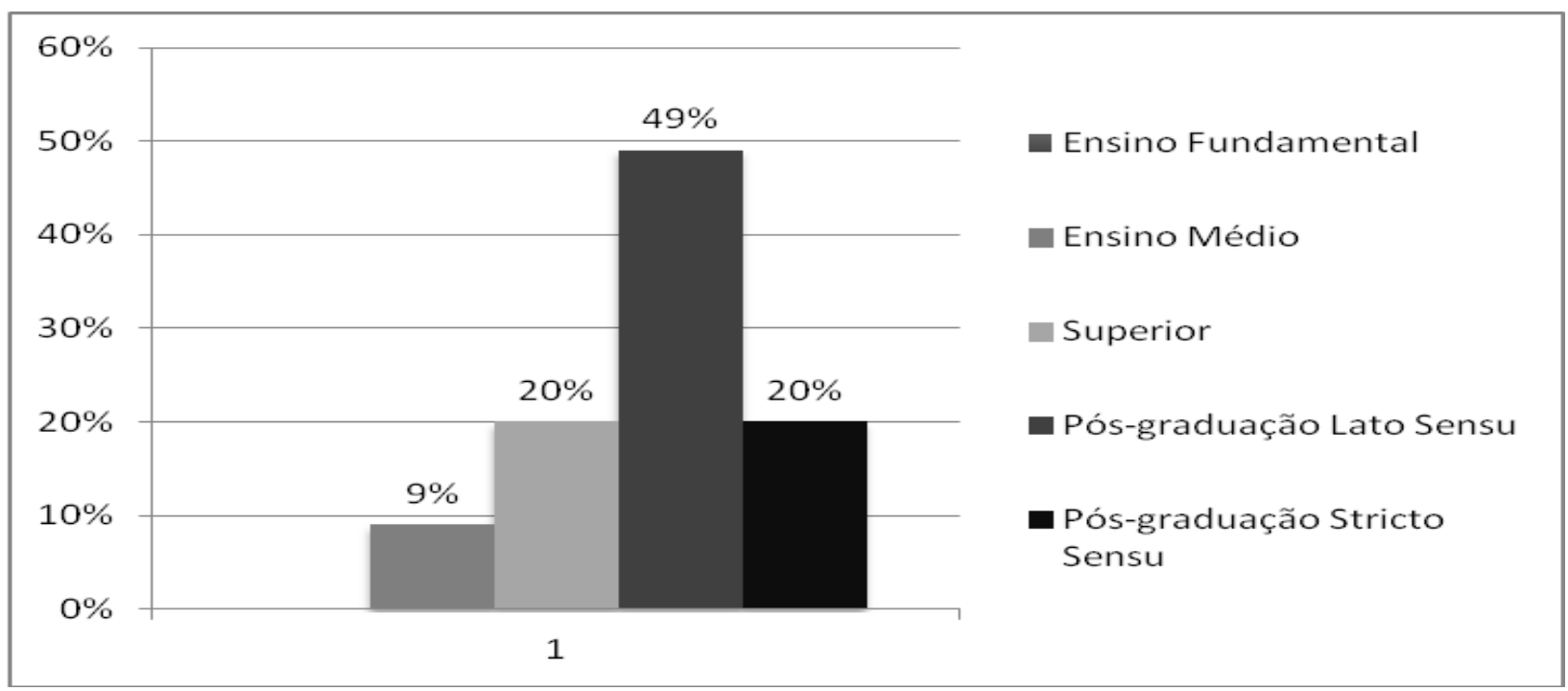

Figura 1. Grau de instrução dos respondentes Fonte: Dados da pesquisa.

Mais da metade (60\%) dos servidores que responderam à pesquisa possuem menos de 10 anos de trabalho no IMA, como mostra a Figura 2. 


\section{Tempo de trabalho no IMA}

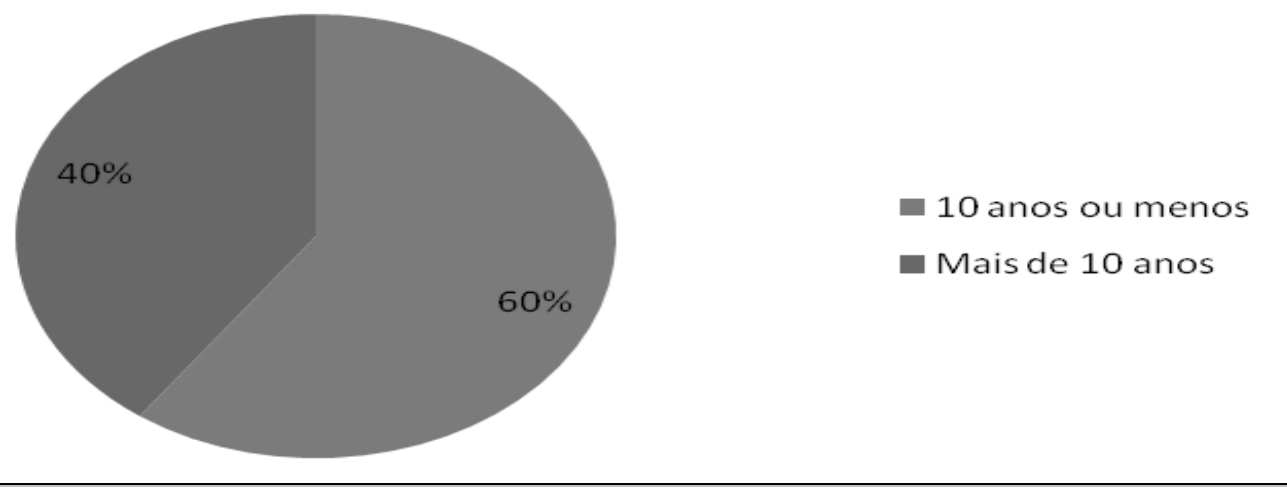

Figura 2. Tempo de trabalho no IMA

Fonte: Dados da pesquisa.

Referente à distribuição por unidade/área, os Escritórios Seccionais foram os setores onde esteve concentrada a maior parte da amostra com 26\%, seguidos da Gerência de Rede Laboratorial, com 24\%, e das Coordenadorias Regionais, com 21\%. Isso significa que a maior parte dos respondentes (77\%) está lotada fora da sede do IMA.

A partir da análise de documentos internos, verificou-se que não há um projeto formal de Gestão de Conhecimento no IMA e sim algumas iniciativas compatíveis com práticas de GC.

\subsection{Percepção dos gestores quanto ao uso de práticas e ferramentas de GC}

A partir da Figura 3 é possível observar que a maioria das práticas e ferramentas de gestão do conhecimento propostas pela literatura ainda não está presente no IMA.

\begin{tabular}{|c|c|c|}
\hline $\begin{array}{l}\text { Estágio de } \\
\text { implantação } \\
\text { no IMA } \\
\end{array}$ & Alcance & Práticas e ferramentas de GC \\
\hline $\begin{array}{l}\text { Não existem } \\
\text { planos para } \\
\text { implantação } \\
\text { (14) }\end{array}$ & Iniciativas isoladas & $\begin{array}{l}\text { Mentoring; coaching; banco de competências organizacionais; } \\
\text { memória organizacional / lições aprendidas / banco de } \\
\text { conhecimentos; sistema de inteligência organizacional / } \\
\text { empresarial / inteligência competitiva; universidade corporativa; } \\
\text { gestão de conteúdo; Gestão Eletrônica de Documentos (GED); } \\
\text { Data Warehouse; Data Mining; Balanced Scorecard (BSC); } \\
\text { Decision Support System (DSS); Indicadores Chaves de } \\
\text { Desempenho (Key Performance Indicator - KPI); Enterprise } \\
\text { Resource Planning - ERP ou SIGE (Sistemas Integrados de } \\
\text { Gestão Empresarial). }\end{array}$ \\
\hline \multirow[t]{2}{*}{$\begin{array}{l}\text { Em processo de } \\
\text { implantação (7) }\end{array}$} & Iniciativas isoladas & $\begin{array}{l}\text { Comunidades de práticas/comunidades de conhecimento; } \\
\text { mapeamento ou auditoria do conhecimento; gestão do capital } \\
\text { intelectual/gestão dos ativos intangíveis; banco de competências } \\
\text { individuais/banco de talentos/páginas amarelas. }\end{array}$ \\
\hline & $\begin{array}{l}\text { Parcialmente } \\
\text { disseminadas }\end{array}$ & Melhores práticas (Best practices). \\
\hline
\end{tabular}




\begin{tabular}{ccl} 
& $\begin{array}{c}\text { Amplamente } \\
\text { disseminadas }\end{array}$ & Narrativas; educação corporativa. \\
\hline Já implantadas & Iniciativas isoladas & $\begin{array}{l}\text { Benchmarking interno e externo; sistemas de workflow; sistema } \\
\text { de gestão por competências }\end{array}$ \\
(5) & $\begin{array}{l}\text { Parcialmente } \\
\text { disseminadas } \\
\text { Amplamente } \\
\text { disseminadas }\end{array}$ & Fóruns (presenciais/virtuais)/lista de discussão \\
& Ferramentas de colaboração como portais intranets e extranet \\
\hline
\end{tabular}

Figura 3. Estágio e alcance de implantação das práticas e ferramentas de GC no IMA, segundo a GRH e a GPM Fonte: Dados da pesquisa.

Das 26 práticas e ferramentas identificadas por Batista et al. (2005), observa-se que: 14 delas não constam ainda nos planos de implantação no IMA, segundo os setores pesquisados. Para eles, existem 7 práticas/ferramentas em estágio de implantação e 5 já implantadas. Dessas, as ferramentas de colaboração, como portais intranets e extranets, foram apontadas como amplamente disseminadas. Nos resultados encontrados por Batista et al. (2005), apenas 9 práticas e ferramentas não existiam planos de implantação nas instituições por ele pesquisadas. Entretanto, dessas 9 práticas e ferramentas, 7 foram mencionadas como existentes no IMA, pelas duas gerências pesquisadas: mentoring, coaching e universidade corporativa (práticas), e Balanced Scorecard (BSC); Decision Support System (DSS); Indicadores Chaves de Desempenho - KPI) e Enterprise Resource Planning - ERP (ferramentas). Este resultado mostra que o IMA já evoluiu em algumas iniciativas importantes, relativas à GC.

\subsection{Percepção dos servidores quanto ao uso de práticas e ferramentas de GC}

Das 26 práticas e ferramentas investigadas quanto ao conhecimento e à frequência de uso pelos servidores do IMA, 18 foram apontadas como desconhecidas pelos respondentes (Tabela 1). Dessas, 13 já haviam sido relatadas pelas gerências de Recursos Humanos e de Planejamento e Modernização Institucional como sem planos para implantação no IMA. Nesse sentido, as ferramentas de apoio à TI, como data warehouse, data mining, decision support system e enterprise resource planning, aparecem com os percentuais mais elevados entre aquelas tidas como desconhecidas pelos respondentes e sem planos para implantação na opinião dos setores estratégicos. Esse fato já fora observado por Gonçalves e Vasconcelos (2011) na Administração Tributária de Minas Gerais. As autoras constataram não haver uniformidade nem planejamento na oferta das ferramentas de tecnologia aos servidores da ATMG. 
Um dado que chama atenção é que, para cinco práticas de GC, a percepção dos servidores foi diferente da apresentada pela GRH e pela GPM. Por exemplo, as práticas benchmarking interno e externo e sistemas de workflow, desconhecidas para $41,5 \%$ e $56,9 \%$ dos respondentes, respectivamente, foram apontadas pelos setores estratégicos como já implantadas, porém como iniciativas isoladas. A gestão do capital intelectual, as narrativas e banco de competências individuais, estão em processo de implantação na visão da GRH e da GPM, mas são desconhecidas para $67,7 \%, 40 \%$ e $50,8 \%$ dos demais servidores, respectivamente.

Esses dados sugerem que as áreas meio e fim do IMA carecem de algum alinhamento quando o assunto é Gestão do Conhecimento, principalmente pelo fato de $77 \%$ dos respondentes estarem lotados fora da sede, o que pode dificultar o acesso a processos desenvolvidos nesse local. Simultaneamente, a julgar pela baixa representatividade da GPM e da GRH na pesquisa com os demais servidores (somando-se as duas gerências, há apenas 5 respondentes), as práticas indicadas como já implantadas, porém com um alcance restrito (iniciativas isoladas), como o benchmarking interno e externo e os sistemas de workflow, podem ser conhecidas e aplicadas apenas nesses dois setores ou ainda em outros setores que não foram representados na pesquisa ou que tiveram poucos respondentes. 
Tabela 1

Percepção dos servidores do IMA quanto ao conhecimento e ao uso de práticas e ferramentas de

GC

\begin{tabular}{|c|c|c|c|c|}
\hline Práticas/ferramentas de GC & Desconheço & $\begin{array}{c}\text { Conheço, } \\
\text { mas não } \\
\text { utilizo }\end{array}$ & $\begin{array}{l}\text { Utilizo com } \\
\text { pouca } \\
\text { frequência }\end{array}$ & $\begin{array}{l}\text { Utilizo } \\
\text { com muita } \\
\text { frequência }\end{array}$ \\
\hline $\begin{array}{l}\text { Comunidade de prática/comunidade de } \\
\text { conhecimento }\end{array}$ & $29,2 \%$ & $32,3 \%$ & $26,2 \%$ & $12,3 \%$ \\
\hline Mentoring & $41,5 \%$ & $35,4 \%$ & $12,3 \%$ & $10,8 \%$ \\
\hline Coaching & $35,4 \%$ & $44,6 \%$ & $13,8 \%$ & $6,2 \%$ \\
\hline Benchmarking interno e externo & $41,5 \%$ & $27,7 \%$ & $15,4 \%$ & $15,4 \%$ \\
\hline Melhores práticas (best practices) & $24,6 \%$ & $30,8 \%$ & $16,9 \%$ & $27,7 \%$ \\
\hline $\begin{array}{l}\text { Fóruns (presenciais e virtuais)/ } \\
\text { lista de discussão }\end{array}$ & $21,5 \%$ & $35,4 \%$ & $29,2 \%$ & $13,9 \%$ \\
\hline $\begin{array}{l}\text { Mapeamento ou auditoria do } \\
\text { conhecimento }\end{array}$ & $29,2 \%$ & $40,0 \%$ & $23,1 \%$ & $7,7 \%$ \\
\hline $\begin{array}{l}\text { Ferramentas de colaboração, como } \\
\text { portais, intranets e extranets }\end{array}$ & $6,2 \%$ & $12,3 \%$ & $30,8 \%$ & $50,8 \%$ \\
\hline Sistema de gestão por competências & $18,5 \%$ & $36,9 \%$ & $30,8 \%$ & $13,9 \%$ \\
\hline Banco de competências organizacionais & $35,4 \%$ & $27,7 \%$ & $20,0 \%$ & $16,9 \%$ \\
\hline $\begin{array}{c}\text { Banco de competências } \\
\text { individuais/banco de talentos/páginas } \\
\text { amarelas }\end{array}$ & $50,8 \%$ & $32,3 \%$ & $13,9 \%$ & $3,1 \%$ \\
\hline $\begin{array}{l}\text { Memória organizacional/lições } \\
\text { aprendidas/banco de conhecimentos }\end{array}$ & $40,0 \%$ & $26,2 \%$ & $23,1 \%$ & $10,8 \%$ \\
\hline $\begin{array}{c}\text { Sistema de inteligência } \\
\text { organizacional / empresarial / } \\
\text { inteligência competitiva }\end{array}$ & $40,0 \%$ & $27,7 \%$ & $16,9 \%$ & $15,4 \%$ \\
\hline Educação corporativa & $29,2 \%$ & $52,3 \%$ & $10,8 \%$ & $7,7 \%$ \\
\hline Universidade Corporativa & $41,5 \%$ & $35,4 \%$ & $16,9 \%$ & $6,2 \%$ \\
\hline Narrativas & $40,0 \%$ & $27,7 \%$ & $24,6 \%$ & $7,7 \%$ \\
\hline Sistemas de workflow & $56,9 \%$ & $18,5 \%$ & $23,1 \%$ & $1,5 \%$ \\
\hline $\begin{array}{l}\text { Gestão do capital intelectual/gestão dos } \\
\text { ativos intangíveis }\end{array}$ & $67,7 \%$ & $20,0 \%$ & $10,8 \%$ & $1,5 \%$ \\
\hline Gestão de conteúdo & $50,8 \%$ & $30,8 \%$ & $10,8 \%$ & $7,7 \%$ \\
\hline Gestão eletrônica de documentos (GED) & $33,9 \%$ & $32,3 \%$ & $15,4 \%$ & $18,5 \%$ \\
\hline Data warehouse & $66,2 \%$ & $15,4 \%$ & $9,2 \%$ & $9,2 \%$ \\
\hline Data mining & $64,6 \%$ & $24,6 \%$ & $4,6 \%$ & $6,2 \%$ \\
\hline Balanced Scorecard (BSC) & $64,6 \%$ & $16,9 \%$ & $15,4 \%$ & $3,1 \%$ \\
\hline Decision Support System (DSS) & $60,0 \%$ & $26,2 \%$ & $10,8 \%$ & $1,5 \%$ \\
\hline $\begin{array}{c}\text { Indicadores chaves de desempenho (Key } \\
\text { Perfomance Indicator - KPI) }\end{array}$ & $60,0 \%$ & $27,7 \%$ & $10,8 \%$ & $3,1 \%$ \\
\hline Enterprise Resource Planning (ERP) & $50,8 \%$ & $27,7 \%$ & $15,4 \%$ & $6,2 \%$ \\
\hline
\end{tabular}

Fonte: Dados da pesquisa.

Há 10 anos, o governo de Minas Gerais deu início à implantação de uma série de processos inovadores, com vários investimentos em ferramentas e práticas de gestão, além de uma conscientização dos servidores quanto à importância da valorização e do uso do conhecimento para a organização. Os projetos visaram a melhoria na prestação do serviço ao cidadão e modernização de organizações públicas estaduais, inclusive no IMA. Por esse motivo, foi analisada a influência do tempo de casa nos resultados, por meio do uso do teste do Qui-quadrado. Assim a expectativa era que houvesse diferença entre as respostas de quem tinha menos de 10 anos de trabalho no IMA, e que não vivenciou a implementação das mudanças, com quem tinha tempo superior a 10 anos. Os valores do teste do Qui-quadrado se encontram na Tabela 2.Tabela 2 
Valores do teste de Qui-quadrado para a variável tempo de trabalho*, com p>0,05

\begin{tabular}{|c|c|c|c|c|c|}
\hline Tempo & $\mathbf{N}$ & Prática/ferramenta & $X^{2}(\mathrm{p})$ & Prática/ferramenta & $X^{2}(\mathrm{p})$ \\
\hline$>10$ anos & 26 & Comunidades de prática & $0,74(\mathrm{p}>0,05)$ & Educação corporativa & $0,12(\mathrm{p}>0,05)$ \\
\hline$<10$ anos & 39 & Mentoring & $3,60(p>0,05)$ & Universidade corporativa & $0,34(\mathrm{p}>0,05)$ \\
\hline \multirow{13}{*}{ Total } & \multirow{13}{*}{65} & Coaching & $2,76(p>0,05)$ & Narrativas & $3,40(p>0,05)$ \\
\hline & & Benchmarking interno e externo & $2,73(\mathrm{p}>0,05)$ & Sistemas de workflow & $2,98(p>0,05)$ \\
\hline & & Melhores práticas & $2,29(\mathrm{p}>0,05)$ & \multirow{2}{*}{$\begin{array}{l}\text { Gestão do capital } \\
\text { intelectual }\end{array}$} & \multirow[t]{2}{*}{$0,00(p>0,05)$} \\
\hline & & Fóruns/listas de discussão & $2,96(\mathrm{p}>0,05)$ & & \\
\hline & & Mapeamento do conhecimento & $2,67(p>0,05)$ & Gestão de conteúdo & $1,42(p>0,05)$ \\
\hline & & Ferramentas de colaboração & $1,34(\mathrm{p}>0,05)$ & Gestão Eletrônica de & $1,15(\mathrm{p}>0,05)$ \\
\hline & & \multirow{2}{*}{$\begin{array}{l}\text { Sistema de gestão por } \\
\text { competência }\end{array}$} & \multirow[t]{2}{*}{$2,80(\mathrm{p}>0,05)$} & \multirow{3}{*}{$\begin{array}{l}\text { Data warehouse } \\
\text { Data Mining } \\
\text { Balanced Scorecard }\end{array}$} & \\
\hline & & & & & $2,81(\mathrm{p}>0,05)$ \\
\hline & & $\begin{array}{l}\text { Banco de competências } \\
\text { organizacionais }\end{array}$ & $1,99(\mathrm{p}>0,05)$ & & $1,27(\mathrm{p}>0,05)$ \\
\hline & & \multirow{2}{*}{$\begin{array}{l}\text { Banco de competências } \\
\text { individuais }\end{array}$} & \multirow{3}{*}{$1,38(\mathrm{p}>0,05)$} & \multirow{3}{*}{$\begin{array}{l}\text { Decision Support System } \\
\text { Indicadores chaves de } \\
\text { desempenho }\end{array}$} & $2,91(\mathrm{p}>0,05)$ \\
\hline & & & & & $0,67(\mathrm{p}>0,05)$ \\
\hline & & Memória organizacional & & & $1,62(\mathrm{p}>0,05)$ \\
\hline & & $\begin{array}{l}\text { Sistemas de inteligência } \\
\text { organizacional }\end{array}$ & $\begin{array}{l}3,41(p>0,05) \\
3,31(p>0,05)\end{array}$ & $\begin{array}{l}\text { Enterprise Resource } \\
\text { Planning }\end{array}$ & $4,66(p>0,05)$ \\
\hline
\end{tabular}

Fonte: Dados da pesquisa.

*Tempo de trabalho> 10anos: 26 servidores; Tempo de trabalho <10 anos: 39 servidores; Total: 65 servidores

Os resultados do teste sugerem, entretanto, que o tempo de trabalho no IMA não influencia a percepção dos servidores quanto ao uso e ao conhecimento das práticas e ferramentas de GC, uma vez que todos os valores da Tabela 2 estão abaixo de 7,81 que é o valor de referência da tabela de Qui-quadrado para $\mathrm{p}=0,05$ e gl (graus de liberdade)=3. Supõe-se então que os servidores com menos de 10 anos já encontraram uma cultura modificada e se integraram a ela.

\subsection{Análise dos Resultados à luz do modelo de Probst, Raub e Romhardt (2002)}

Quanto aos processos essenciais do conhecimento de Probst, Raub e Romhardt (2002), os resultados encontrados estão dispostos nas Tabelas 3 à 8:

a) Quanto à aquisição, as empresas importam parte de seu conhecimento de fontes externas como clientes, fornecedores, parceiros. Observa-se, no entanto, que o conhecimento necessário aos servidores para a execução de seus trabalhos, conforme a opinião de $38,5 \%$ dos respondentes, frequentemente é encontrado na organização (Tabela 3).

Tabela 3 
Percepção dos servidores quanto aos elementos construtivos da gestão do conhecimento, segundo Probst,

Raub e Romhardt (2002) - Aquisição

\begin{tabular}{|c|c|c|c|c|c|c|}
\hline Etapa & Pergunta/Frequência & Nunca & Raramente & Às vezes & Frequentemente & Sempre \\
\hline \multirow{3}{*}{ Aquisição } & $\begin{array}{l}\text { 1.Você busca } \\
\text { conhecimento fora do } \\
\text { IMA para a conclusão de } \\
\text { seus trabalhos? }\end{array}$ & $3,1 \%$ & $4,6 \%$ & $35,4 \%$ & $29,2 \%$ & $27,7 \%$ \\
\hline & $\begin{array}{l}2.0 \text { conhecimento } \\
\text { necessário para seu } \\
\text { trabalho é encontrado no } \\
\text { IMA? }\end{array}$ & $4,6 \%$ & $15,4 \%$ & $32,3 \%$ & $38,5 \%$ & $9,2 \%$ \\
\hline & Média & $3,9 \%$ & $10,0 \%$ & $33,9 \%$ & $33,9 \%$ & $18,5 \%$ \\
\hline
\end{tabular}

Fonte: Dados da pesquisa.

b) Para a etapa de desenvolvimento do conhecimento, existe um equilíbrio entre as respostas, uma vez que os percentuais para "nunca", "raramente" e "às vezes" foram semelhantes (Tabela 4). O foco do desenvolvimento do conhecimento está na geração de novos produtos, ideias melhores e processos mais eficientes, o que parece não ocorrer no IMA.

Tabela 4

Percepção dos servidores quanto aos elementos construtivos da gestão do conhecimento, segundo Probst, Raub e Romhardt (2002) - Desenvolvimento

\begin{tabular}{|c|c|c|c|c|c|c|}
\hline Etapa & Pergunta/Frequência & Nunca & Raramente & $\begin{array}{c}\text { Às } \\
\text { vezes }\end{array}$ & Frequentemente & Sempre \\
\hline \multirow{3}{*}{ Desenvolvimento } & $\begin{array}{l}\text { 3.Há estímulos ou } \\
\text { esforços por parte da } \\
\text { gerência de registrar seu } \\
\text { conhecimento para o } \\
\text { IMA? }\end{array}$ & $30,8 \%$ & $27,7 \%$ & $21,5 \%$ & $15,4 \%$ & $4,6 \%$ \\
\hline & $\begin{array}{l}\text { 4.Você já participou de } \\
\text { discussão (seminários, } \\
\text { reuniões, workshops) } \\
\text { para desenvolvimento } \\
\text { ou aperfeiçoamento de } \\
\text { técnicas ou de } \\
\text { conhecimentos para o } \\
\text { IMA? }\end{array}$ & $23,1 \%$ & $27,7 \%$ & $32,3 \%$ & $15,4 \%$ & $1,5 \%$ \\
\hline & Média & $26,9 \%$ & $27,7 \%$ & $26,9 \%$ & $15,4 \%$ & $3,1 \%$ \\
\hline
\end{tabular}

Fonte: Dados da pesquisa.

c) No tocante ao compartilhamento de conhecimento, 43,1\% dos servidores afirmaram trocar frequentemente informações e conhecimentos com os outros colegas de maneira formal e informal (Tabela 5). Porém, isso não é feito utilizando-se, por exemplo, da ferramenta fórum/lista de discussão, pois $35,4 \%$ das pessoas pesquisadas afirmaram conhecer a ferramenta, mas não a utilizam, conforme o disposto na Tabela 1. 
Tabela 5

Percepção dos servidores quanto aos elementos construtivos da gestão do conhecimento, segundo Probst, Raub e Romhardt (2002) - Compartilhamento

\begin{tabular}{|c|c|c|c|c|c|c|}
\hline Etapa & Pergunta/Frequência & Nunca & Raramente & $\begin{array}{c}\text { Às } \\
\text { vezes }\end{array}$ & Frequentemente & Sempre \\
\hline \multirow{3}{*}{ Compartilhamento } & $\begin{array}{lr}\text { 5.Você } & \text { troca } \\
\text { informações } & \mathrm{e} \\
\text { conhecimentos } & \mathrm{de} \\
\text { maneira } & \text { informal } \\
\text { (conversas de corredor) } \\
\text { com outros integrantes } \\
\text { do IMA? }\end{array}$ & $0,0 \%$ & $6,2 \%$ & $20,0 \%$ & $44,6 \%$ & $29,2 \%$ \\
\hline & $\begin{array}{lr}\text { 6.Você } & \text { troca } \\
\text { informações } & \mathrm{e} \\
\text { conhecimentos } & \mathrm{de} \\
\text { maneira } & \text { formal } \\
\text { (sistemas, e-mails) com } & \text { com } \\
\text { outros integrantes do } & \\
\text { IMA? } & \end{array}$ & $7,7 \%$ & $13,9 \%$ & $13,9 \%$ & $41,5 \%$ & $23,1 \%$ \\
\hline & Média & $3,9 \%$ & $10,0 \%$ & $16,9 \%$ & $43,1 \%$ & $26,2 \%$ \\
\hline
\end{tabular}

Fonte: Dados da pesquisa.

d) Os elementos utilização, retenção e identificação do conhecimento são utilizados "às vezes", segundo os respondentes, isto é, de forma esporádica. Os respectivos percentuais 48,7\% (Tabela 6), 27,7\% (Tabela 7) e 47,2\% (Tabela 8) confirmam essa situação, principalmente no que diz respeito à utilização e à identificação do conhecimento, cujos resultados foram mais expressivos. 
Tabela 6

Percepção dos servidores quanto aos elementos construtivos da gestão do conhecimento, segundo Probst, Raub e Romhardt (2002) - Utilização

\begin{tabular}{|c|c|c|c|c|c|c|}
\hline Etapa & Pergunta/Frequência & Nunca & Raramente & Ás vezes & Frequentemente & Sempre \\
\hline \multirow{4}{*}{ Utilização } & $\begin{array}{l}\text { 7.As fontes de } \\
\text { informações técnicas } \\
\text { (banco de dados, sistemas } \\
\text { etc.) estão estruturadas de } \\
\text { maneira favorável aos } \\
\text { usuários? }\end{array}$ & $6,2 \%$ & $24,6 \%$ & $50,8 \%$ & $15,4 \%$ & $3,1 \%$ \\
\hline & $\begin{array}{l}\text { 8.Os locais onde é } \\
\text { desenvolvido o trabalho } \\
\text { estão equipados e } \\
\text { apresentam ambiente } \\
\text { adequado que estimula a } \\
\text { utilização do } \\
\text { conhecimento relevante? }\end{array}$ & $3,1 \%$ & $26,2 \%$ & $40,0 \%$ & $23,1 \%$ & $7,7 \%$ \\
\hline & $\begin{array}{lr}\text { 9.As informações } & \text { e } \\
\text { conhecimento de } & \text { que } \\
\text { você precisa } & \text { para } \\
\text { desenvolvimento } & \text { do } \\
\text { trabalho podem } & \text { ser } \\
\text { encontrados } & \text { com } \\
\text { facilidade? } & \\
\end{array}$ & $3,1 \%$ & $12,3 \%$ & $55,4 \%$ & $23,1 \%$ & $6,2 \%$ \\
\hline & Média & $4,1 \%$ & $21,0 \%$ & $48,7 \%$ & $20,5 \%$ & $5,6 \%$ \\
\hline
\end{tabular}

Fonte: Dados da pesquisa.

Para Probst, Raub e Romhardt (2002), o objetivo integral da gestão do conhecimento é assegurar que o conhecimento existente em uma organização seja aplicado de forma produtiva. No caso do IMA, apesar de os servidores afirmarem compartilhar frequentemente o conhecimento, não se pode concluir que o que é compartilhado é de fato utilizado, visto que, para as questões referentes à utilização do conhecimento (Tabela 6), quase metade $(48,7 \%)$ dos servidores escolheram "às vezes" para representar a frequência com que utilizam o conhecimento organizacional. 
Tabela 7

Percepção dos servidores quanto aos elementos construtivos da gestão do conhecimento, segundo Probst, Raub e Romhardt (2002) - Retenção

\begin{tabular}{|c|c|c|c|c|c|c|}
\hline Etapa & Pergunta/Frequência & Nunca & Raramente & $\begin{array}{c}\text { Às } \\
\text { vezes }\end{array}$ & Frequentemente & Sempre \\
\hline \multirow[t]{3}{*}{ Retenção } & $\begin{array}{l}\text { 10.Quando você é } \\
\text { transferido de um } \\
\text { trabalho para outro, o } \\
\text { seu conhecimento } \\
\text { adquirido é arquivado } \\
\text { para uso de outros } \\
\text { colegas? }\end{array}$ & $18,5 \%$ & $15,4 \%$ & $27,7 \%$ & $24,6 \%$ & $13,9 \%$ \\
\hline & $\begin{array}{l}\text { 11.Você tem acesso a } \\
\text { consultas sobre } \\
\text { trabalhos e projetos } \\
\text { desenvolvidos no IMA? }\end{array}$ & $15,4 \%$ & $38,5 \%$ & $27,7 \%$ & $13,9 \%$ & $4,6 \%$ \\
\hline & Média & $16,9 \%$ & $26,9 \%$ & $27,7 \%$ & $19,2 \%$ & $9,2 \%$ \\
\hline
\end{tabular}

Fonte: Dados da pesquisa.

A gestão eficaz do conhecimento deve ajudar os funcionários a localizarem o que precisam (PROBST; RAUB; ROMHARDT, 2002). Contudo, os resultados da Tabela 8 sugerem que isso ocorre de modo esporádico na organização, uma vez que $40 \%$ dos respondentes afirmaram que "às vezes" já necessitaram de um especialista interno para discutir uma dificuldade ou tema de trabalho, e não o localizaram. Aproximadamente, metade dos servidores pesquisados respondeu, ainda, que "às vezes" já ocorreu do conhecimento para a realização do trabalho estar teoricamente disponível, mas que eles não conseguiram obtê-lo a tempo. Não se pode afirmar, portanto, que o processo identificação do conhecimento esteja estabelecido no IMA. Um percentual de $41,5 \%$ dos respondentes afirmaram desconhecer a prática benchmarking, que ajuda as empresas a identificarem as melhores práticas dentro e fora da organização, bem como os pontos fracos e de melhoria (Tabela 1), o que, de certa maneira, reforça a afirmação anterior. 
Tabela 8

Percepção dos servidores quanto aos elementos construtivos da gestão do conhecimento, segundo Probst, Raub e Romhardt (2002) - Identificação

\begin{tabular}{|c|c|c|c|c|c|c|}
\hline Etapa & Pergunta/Frequência & Nunca & Raramente & $\begin{array}{c}\grave{\text { Ass }} \\
\text { vezes }\end{array}$ & Frequentemente & Sempre \\
\hline \multirow{4}{*}{ Identificação } & $\begin{array}{l}\text { 12.Você já necessitou } \\
\text { de um especialista } \\
\text { interno do IMA para } \\
\text { discutir uma dificuldade } \\
\text { ou tema de trabalho, e } \\
\text { não o localizou? }\end{array}$ & $13,9 \%$ & $24,6 \%$ & $40,0 \%$ & $15,4 \%$ & $6,2 \%$ \\
\hline & $\begin{array}{l}\text { 13.O conhecimento } \\
\text { necessário para seu } \\
\text { trabalho } \\
\text { teoricamente } \\
\text { disponível. Já ocorreu } \\
\text { de você não o conhecer } \\
\text { ou não o ter obtido a } \\
\text { tempo? }\end{array}$ & $13,9 \%$ & $21,5 \%$ & $49,2 \%$ & $21,5 \%$ & $4,6 \%$ \\
\hline & $\begin{array}{lr}\text { 14.Os } & \text { sistemas } \\
\text { disponíveis de busca de } \\
\text { informações } & \text { são } \\
\text { suficientes para a sua } \\
\text { demanda? }\end{array}$ & $6,2 \%$ & $15,4 \%$ & $52,3 \%$ & $21,5 \%$ & $4,6 \%$ \\
\hline & Média & $11,3 \%$ & $20,5 \%$ & $47,2 \%$ & $19,5 \%$ & $5,1 \%$ \\
\hline
\end{tabular}

Fonte: Dados da pesquisa.

No que concerne à utilização dos elementos essenciais do conhecimento segundo Probst, Raub e Romhardt (2002), a partir das tabelas apresentadas é possível inferir que somente os processos relacionados ao compartilhamento de conhecimento são utilizados de forma frequente. Os demais, de uma forma geral, são utilizados esporadicamente.

\section{Conclusões}

Este estudo teve como proposta investigar práticas e ferramentas de gestão do conhecimento utilizadas no Instituto Mineiro de Agropecuária. Os dados obtidos apontam para a presença de algumas práticas e ferramentas de GC descritas na literatura. Essas, conforme opinião de alguns gestores do IMA, encontram-se já implantadas ou estão em processo de implantação.

Mesmo assim, várias dessas práticas e ferramentas implantadas ainda não são conhecidas pelos servidores do IMA. As ferramentas de TI, como data warehouse, data mining e decision support system (DSS), por exemplo, são desconhecidas por mais da metade dos respondentes. Apesar disso, a maioria dos servidores afirmou utilizar com muita frequência portais colaborativos, como intranet e extranet. $\mathrm{O}$ uso de portais colaborativos é algo positivo para a instituição, pois essas soluções de TI favorecem, facilitam e permitem o acesso a informações 
e aplicações importantes, funcionando como uma plataforma de repositório do conhecimento e como um ambiente de integração interna e externa.

No tocante aos processos essenciais da gestão do conhecimento propostos por Probst, Raub e Romhardt (2002) e utilizados neste artigo, as respostas dos servidores sinalizam que o compartilhamento está presente, de fato, no cotidiano dessas pessoas, tanto de maneira formal quanto informal. Verificou-se, no entanto, que as demais etapas não são tão utilizadas, sendo, portanto, difícil de encontrá-las. Nesse sentido, a organização poderia promover ações que buscassem desenvolver e, principalmente, registrar o conhecimento de seus servidores. Poderia, ainda, criar mecanismos (ou disponibilizar melhor os existentes) que facilitassem a rápida identificação de pessoas e processos necessários à execução dos trabalhos dos servidores. O banco de competências individuais e organizacionais e o mapeamento de processos poderiam ser úteis nesse caso.

Entretanto, para que essas transformações de fato aconteçam, é preciso, sobretudo, o comprometimento de todos, desde a alta administração até os servidores do nível operacional, pois os processos do setor público costumam ocorrer de forma mais lenta do que ocorrem na iniciativa privada, seja por descontinuidade nas políticas governamentais, seja pela manutenção do status quo.

Visto o papel fundamental que o Instituto Mineiro de Agropecuária possui para a administração pública mineira, o diagnóstico realizado a partir dessa pesquisa poderá favorecer a implantação efetiva da GC, permitindo a identificação e o direcionamento de ações mais efetivas e a melhoria dos seus processos. 


\section{REFERÊNCIAS}

ALVARENGA NETO, R. C. D. (2005). Gestão do conhecimento em organizações: proposta de mapeamento conceitual integrativo. Tese de doutorado, Universidade Federal de Minas Gerais, Belo Horizonte, MG, Brasil.

ANGELONI, M. T. (Coord.). (2008). Organizações do conhecimento: Infraestrutura, Pessoas e Tecnologias. 2.ed. São Paulo: Saraiva.

BATISTA, F.F. (2004). Governo que aprende: Gestão do conhecimento em organizações do executivo Federal. [Tex to para discussão $N^{\circ}$ 1022]. Brasília, DF: IPEA.

BATISTA, F. F., QUANDT, O. C., PACHECO, F. F, \& TERRA, J. C. C. (2005). Gestão do Conhecimento na Administração Pública. [Texto para discussão $\mathrm{N}^{\circ} 1095$ ]. Brasília, DF: IPEA.

BATISTA, F. F. (2012). Gestão do Conhecimento na Administração Pública. Brasília: IPEA.

COELHO, E. M. (2004). Gestão do conhecimento como sistema de gestão para o setor público. Revista do Serviço Público, Brasília, n.1-2, p.89-115.

GONÇALVES, S. F. R. (2010). Gestão do Conhecimento: Análise de Práticas e Ferramentas no âmbito da Administração Tributária de Minas Gerais. Dissertação de Mestrado, Faculdades Pedro Leopoldo, Pedro Leopoldo, MG, Brasil.

GONÇALVES, S. F. R., \& VASCONCELOS, M.C.R.L. de. (2011, setembro). Práticas e Ferramentas de Gestão do Conhecimento no Âmbito da Administração Tributária de Minas Gerais: Oportunidade para uma Política Institucional, Anais do Encontro Nacional da Associação Nacional de Pós-graduação e Pesquisa em Administração, Rio de Janeiro, RJ, Brasil, 25.

GONÇALVES, S. F. R.; VASCONCELOS, M. C. R. L.; CARVALHO, R. B.; NEVES, J. T.(2012) . Práticas e ferramentas de gestão do conhecimento no âmbito da administração tributária de Minas Gerais: oportunidade para uma política institucional. Revista de Gestão e Projetos, v. 3, p. 207-234. ISSN/ISBN: 22360972.

NEVES, F. DE S., \& SILVA, M. F. J. DA. (2009). Uma reflexão sobre o novo modelo de cargos comissionados do estado: flexibilidade com foco em resultados. Pôster Sessão 
Meritocracia e cargos comissionados apresentado no Congresso Consad de Gestão Pública, Brasília, DF, Brasil, 2.

PROBST, G., RAUB, S., \& ROMHARDT, K. (2002). Gestão do conhecimento: os elementos construtivos do sucesso. Porto Alegre: Bookman.

REIS, V. DOS. (2007). Gestão do conhecimento e cultura organizacional: um estudo de caso na Fiocruz-Bahia. Dissertação de Mestrado Centro de Pesquisas Aggeu Magalhães, Fundação Oswaldo Cruz, Recife, Pernambuco, Brasil.

SANTOS, S. A. DOS (Org.).(2007). Gestão do conhecimento: Institucionalização e práticas nas empresas e instituições. Maringá: Unicorpore.

SETZER, V. W. Dado, informação, conhecimento e competência (1999). DataGramaZero Revista de Ciência da Informação, n. zero, dez/99. Recuperado em 13 de novembro de 2011, de http://www.dgz.org.br/dez99/Art_01.htm

VASCONCELOS, M. C. R. L. DE. (2000). Cooperação Universidade Empresa na PósGraduação: Contribuição para a Aprendizagem, a Gestão do Conhecimento e a Inovação na Indústria Mineira. Tese de Doutorado, Universidade Federal de Minas Gerais, Belo Horizonte, MG, Brasil.

YIN, R. K. (2001). Estudo de caso: planejamento e métodos (2a ed., D. Grassi, Trad.). Porto Alegre: Bookman. (Obra original publicada em 1984). 